\title{
Assessment of Cancer Antigen 125 in Post-HCV Chronic Liver Disease and Hepatocellular Carcinoma Patients
}

\author{
Rania F El-Folly ${ }^{1}$, Heba H Ali ${ }^{2}$, Nevien F EL-Fouly ${ }^{3}$ \\ ${ }^{1}$ Tropical Medicine Department, Faculty of Medicine, Ain Shams University, Cairo, Egypt \\ ${ }^{2}$ Clinical Pathology Department, Faculty of Medicine, Ain Shams University, Cairo, Egypt \\ ${ }^{3}$ Tropical Medicine, Department of Health Research, National Center for Radiation Research \\ and Technology, Atomic Energy Authority, Cairo, Egypt.
}

Corresponding Author Nevien F EL-Fouly

Mobile:

$+201226750040$

\section{E mail:}

novaelfouly@yahoo. com

Key words: Hepatocellular carcinoma; Cancer antigen 125; Post $\mathrm{HCV}$ chronic liver disease

Short title: serum CA125 and CLD patients with or without HCC.
Background and study aim: Most of the morbidity and mortality of chronic liver diseases is due to its progression and complication of cirrhosis as ascites. The cancer antigen (CA) -125 is a high molecular mass glycoprotein produced both by ovarian cancer cells as well as by normal cells derived from coelomic epithelium. This study was conducted to assess the serum and/or ascitic fluid level of CA125 in HCV cirrhotic patients (decompensated or not) with or without Hepatocellular Carcinoma (HCC).

Patients and Methods: Group I: 60 post HCV liver cirrhoses cases; (A) 30 cases without ascites, (B) 30 cases with ascites. Group II: $60 \mathrm{HCC}$ of post $\mathrm{HCV}$ liver cirrhosis cases; (C) 30 cases without ascites, (D) 30 cases with ascites. Serum and ascetic fluid level of CA-125 as well as serum AFP were assessed in all cases.
Results: Serum level of CA-125 between group $\mathrm{A} \& \mathrm{~B}$ being higher in group $\mathrm{B}$ $(\mathrm{P}<0.01)$, however between groups $\mathrm{C} \& \mathrm{D}$ being higher in group $\mathrm{D}(\mathrm{P}<0.01)$. There was a positive correlation between serum level of CA-125 and AFP level in group $A$ and $C(P>0.05)$. Regarding Group B and $\mathrm{D}$, there was a positive correlation between serum level of CA-125 and each of AFP level $(\mathrm{P}>0.05)$ and ascitic level of CA-125 $(\mathrm{P}<0.01)$. Concerning the ascitic level of $\mathrm{Ca} 125$, being higher in group $\mathrm{D}$ than $\mathrm{B}(\mathrm{P}<0.01)$. Only AFP had a significant diagnostic performance $(\mathrm{P}<0.01)$ in differentiating HCC groups from nonHCC groups.

Conclusion: Elevated serum and ascetic level of CA125 in decompensated cirrhosis with or without HCC. AFP had a diagnostic performance in HCC diagnosis.

\section{INTRODUCTION}

Chronic liver diseases and their complications constitute a major health problem all over the world and especially in our country [1]. Most of the morbidity and mortality of chronic liver diseases is due to its progression and complications of cirrhosis [2]. Ascites is a frequent complication of advanced liver cirrhosis. Over $50 \%$ of cirrhotic patients develop ascites due to increased sodium retention in the kidneys, leading to expansion of extracellular volume and accumulation of fluid in the peritoneum [3]. The cancer antigen (CA) -125 is a high molecular mass glycoprotein produced both by ovarian cancer epithelial cells and mesothelial cells [4].
Serum CA-125 levels are used as a marker of tumour activity in patients known to have ovarian carcinoma [5], the severity of liver disease evaluated by MELD score and the presence of ascites were significantly correlated with the elevation of CA-125 level [6]. Serum CA-125 levels are generally found to be higher in malignant conditions compared to benign conditions. Levels exceeding 1000 $\mathrm{U} / \mathrm{ml}$ have been described in benign conditions associated with massive pleural effusion and ascites [7].

Hepatocellular carcinoma (HCC) is a global problem worldwide. Egypt is the sixth country in the Middle East and Arab world and the third one in Africa, with a high prevalence of $\mathrm{HCC}$, the major risk factor for HCC is $\mathrm{HCV}$ infection which mainly burden 
in Egypt [8]. Alpha fetoprotein (AFP) is a fetal specific glycoprotein; more than $70 \%$ of HCC patients have a high serum concentration of AFP because of the tumor excretion [9]. AFP serves as an important tool in screening of HCC patients; however patients with acute exacerbation of viral hepatitis and not associated with HCC may also have markedly increased AFP levels [10]. Together, AFP (cut-off: $200 \mathrm{ng} / \mathrm{mL}$ ) and CA 125 have been reported to give a combined sensitivity of $96 \%$. The use of AFP (sensitivity 58.8\%, specificity of $97.4 \%$ ) and CA125 (sensitivity of $92 \%$, specificity $48.5 \%$ ) together as screening blood markers for HCC has been suggested, a negative result for both markers would most likely rule out HCC [11].

As no enough Egyptian studies were done on the validity of CA-125 and chronic liver diseases or HCC patients, so we aimed to assess the serum and/or ascitic fluid level of CA125 in post HCV cirrhotic patients (decompensated or not) with or without HCC.

\section{PATIENTS AND METHODS}

Study design: A cross sectional observational study

Patients: patients were recruited from those attending Tropical Medicine Department-Ain Shams University and from Professor Doctor Yassin Abdel Gaffar Charity Center for Liver Disease and Research. The study included number of (120) cases and divided into two groups: Group I; Formed of 60 post HCV liver cirrhosis cases; (A) 30 cases without ascites, (B) 30 cases with ascites. Group II; Formed of 60 HCC on top of post HCV liver cirrhosis cases; (C) 30 cases without ascites, (D) 30 cases with ascites. Inclusion Criteria: Male Patients, Clinical, laboratory and ultrasonographic criteria suggestive of chronic liver disease post HCV liver cirrhosis, HCC cases were diagnosed by; High AFP > cut-off limit (>200ng), Characteristic features of HCC by triphasic spiral abdominal CT [12]. Exclusion Criteria: Patients with other causes of liver disease, extrahepatic metastasis or other simultaneous malignancies, Patients with advanced systemic disease and other causes of ascites or serous sac effusion.

Serum and ascetic fluid level of CA-125 were assessed and measured: Specimen collection and preparation: $5 \mathrm{ml}$ of venous blood as well as an ascitic sample were taken under complete aseptic conditions. Instrument: The Roche diagnostics cobas e 411 analyzer was used. Steps of test: Sandwich principle, total duration of assay: 18 minutes. Normal range of CA125 serum level: up to $21 \mathrm{u} / \mathrm{ml}$, Ascitic fluid level: up to $35 \mathrm{u} / \mathrm{ml}$ [13].

\section{Statistical analysis}

IBM SPSS statistics (V. 19.0, IBM Corp., USA, 2010) was used for data analysis. Data were expressed as Mean \pm SD for quantitative parametric measures in addition to Median Percentiles for quantitative non-parametric measures and both number and percentage for categorized data.

The following tests were done: (1) Comparison between two independent groups for non-parametric data using Wilcoxon Rank Sum test. (2) Ranked Sperman correlation test to study the possible association between each two variables among each group for non-parameteric data. (3) Chisquare test to study the association between each 2 variables or comparison between 2 independent groups as regards the categorized data. The probability of error at 0.05 was considered sig., while at 0.01 was considered highly sig. (4) The ROC was constructed to evaluate the most discriminating markers between the compared groups, AUC can also be calculated.

\section{RESULTS}

In order to fulfill our aim, (120) cases were included and divided into two groups; Group I: included 60 post HCV liver cirrhoses cases; (A) (30) patients with compensated cirrhoses. (B) (30) patients with decompensated cirrhosis. Group II: included $60 \mathrm{HCC}$ of post HCV liver cirrhosis cases; (C) 30 cases with compensated cirrhoses, (D) 30 cases with decompensated cirrhosis.

Concerning serum level of CA-125; there was a significant difference between groups (A) \& (B) being higher in group $(\mathrm{B})(\mathrm{P}<0.01)$, also a significant difference between groups (C) \& (D) being higher in group (D) $(\mathrm{P}<0.01)$ as in Table (1).

In Table (2) and (3): There were a positive correlation between serum level of CA-125 and AFP in group (A) and (C) $(\mathrm{P}>0.05)$. Regarding Group (B) and (D), there was a positive correlation between serum level of CA-125 and each of AFP level $(\mathrm{P}>0.05)$ and ascitic level of CA-125 $(\mathrm{P}<0.01)$. Table (4) shows that there was a significant difference between groups B (decompensated non HCC) \& D (decompensated HCC) concerning 
ascitic level of $\mathrm{Ca} 125$ being higher in group $\mathrm{D}$ $(\mathrm{P}<0.01)$.

Regarding the diagnostic performance of AFP and serum CA125 in differentiating compensated HCC group (C) from non-HCC group (A), as in Fig. (1); Only AFP had significant diagnostic performance $(\mathrm{P}<0.01)$ in differentiating compensated HCC group (C) from non-HCC group (A). However, diagnostic performance of AFP, serum CA125 and ascetic fluid CA125 in differentiating decompensated HCC (D) group from non-HCC (B) group as in Figure (2); Only AFP had significant diagnostic performance in differentiating decompensated HCC (D) group from non-HCC (B).

Table (1): Comparison between studied groups concerning serum levels of CA-125

\begin{tabular}{|c|c|c|c|c|}
\hline Variables & Measures & $\begin{array}{c}\text { Group A } \\
(\mathbf{N}=15)\end{array}$ & $\begin{array}{c}\text { Group B } \\
(\mathbf{N}=15)\end{array}$ & $\mathbf{P}$ \\
\hline \multirow{2}{*}{$\begin{array}{l}\text { Serum } \\
\text { CA125 }\end{array}$} & Median (IQR) & $\begin{array}{c}15.7 \\
(9.7-44.0)\end{array}$ & $\begin{array}{c}229.3 \\
(116.9-524.3)\end{array}$ & \multirow{2}{*}{$a<0.001 *$} \\
\hline & Range & $3.5-179.0$ & $32.0-2412.7$ & \\
\hline Variables & Measures & $\begin{array}{c}\text { Group C } \\
(\mathrm{N}=15)\end{array}$ & $\begin{array}{c}\text { Group D } \\
(\mathrm{N}=15)\end{array}$ & $\mathbf{P}$ \\
\hline \multirow{2}{*}{$\begin{array}{l}\text { Serum } \\
\text { CA125 }\end{array}$} & Median (IQR) & $\begin{array}{c}44.4 \\
(9.8-73.0) \\
\end{array}$ & $\begin{array}{c}224.6 \\
(191.6-464.4) \\
\end{array}$ & \multirow[t]{2}{*}{$a<0.001 *$} \\
\hline & Range & $1.0-164.0$ & $62.8-819.0$ & \\
\hline
\end{tabular}

IQR: $1^{\text {st }}-3^{\text {rd }}$ interquartiles, aMann Whitney test, ${ }^{\wedge}$ Independent t-test, $*$ Significant

Decompensated HCC (D) had significantly higher serum CA125 and decompensated non-HCC (B) had significantly higher serum CA125.

Table (2): Correlation between CA-125 serum level and other parameters in group A and B

\begin{tabular}{|l|l|c|c|c|c|}
\hline \multirow{2}{*}{ Variables } & \multirow{2}{*}{ Mean \pm SD } & \multicolumn{3}{|c|}{ CA-125 } \\
\cline { 4 - 6 } \multicolumn{2}{|l|}{} & & $\mathbf{3 4 . 7 7} \pm \mathbf{4 4 . 7 8}$ \\
\hline Group (A) & AFP (Up to 10ng/ml) & $9.867 \pm 5.8$ & 0.145 & 0.444 & NS \\
\hline \multirow{3}{*}{ Group (B) } & AFP (Up to 10ng/ml) & $9.93 \pm 10.18$ & 0.023 & 0.903 & NS \\
\cline { 2 - 6 } & Ascitic CA-125 & $\mathbf{5 0 5 . 4 6} \pm \mathbf{4 3 8 . 6}$ & $\mathbf{0 . 1 5}$ & $\mathbf{0 . 0 0 5}$ & HS \\
\cline { 2 - 6 } & Ascitic PMN & $116 \pm 120$ & 0.13 & 0.492 & NS \\
\hline
\end{tabular}

Ranked Sperman Correlation Test

NB: Highly significant; HS $<0.01$, Significant; $\mathrm{S}<0.05$, Non-significant; NS $>0.05$

PMN: polymorphonuclear leukocytes.

Table (3): Correlation between CA-125 serum levels and other parameters in group C and D

\begin{tabular}{|l|l|c|c|c|c|}
\hline \multicolumn{2}{|c|}{ Variables } & \multirow{2}{*}{ Mean \pm SD } & \multicolumn{3}{|c|}{ CA-125 } \\
\cline { 4 - 6 } \multicolumn{2}{|c|}{} & & R4.77 $\pm \mathbf{4 4 . 7 8}$ \\
\hline Group (C) & AFP (Up to $10 \mathrm{ng} / \mathrm{ml}$ ) & $282 \pm 400.3$ & -0.146 & 0.44 & NS \\
\hline \multirow{3}{*}{ Group (D) } & AFP (Up to $10 \mathrm{ng} / \mathrm{ml})$ & $990.9 \pm 614$ & -0.052 & 0.786 & NS \\
\cline { 2 - 6 } & Ascitic CA-125 & $\mathbf{7 3 4 . 0 1 3} \pm \mathbf{3 9 1 . 3}$ & $\mathbf{0 . 7 8 6}$ & $\mathbf{0}$ & HS \\
\cline { 2 - 6 } & Ascitic PMN & $\mathbf{9 7} \pm \mathbf{5 3 . 6}$ & $\mathbf{0 . 5 0 6}$ & $\mathbf{0 . 0 0 4}$ & HS \\
\hline
\end{tabular}

Ranked Sperman Correlation Test

NB: Highly significant; HS $<0.01$, Significant; $S<0.05$, Non-significant; NS $>0.05$

PMN: polymorphonuclear leukocytes. 
Table (4): Comparison between group B and group D concerning ascitic levels of CA-125

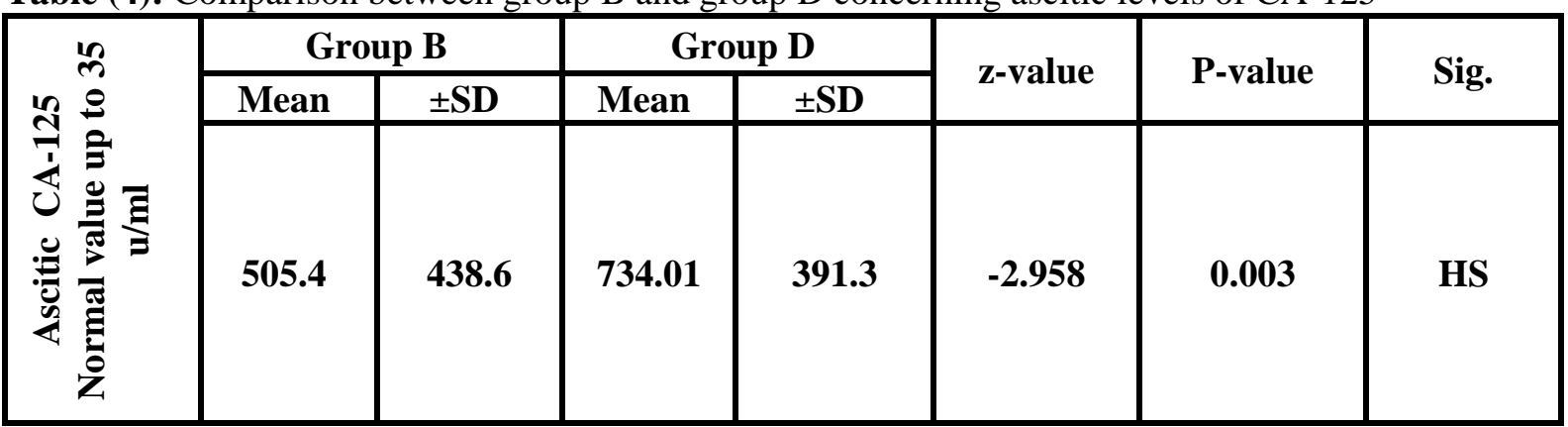

Wilcoxon Rank Sum Test

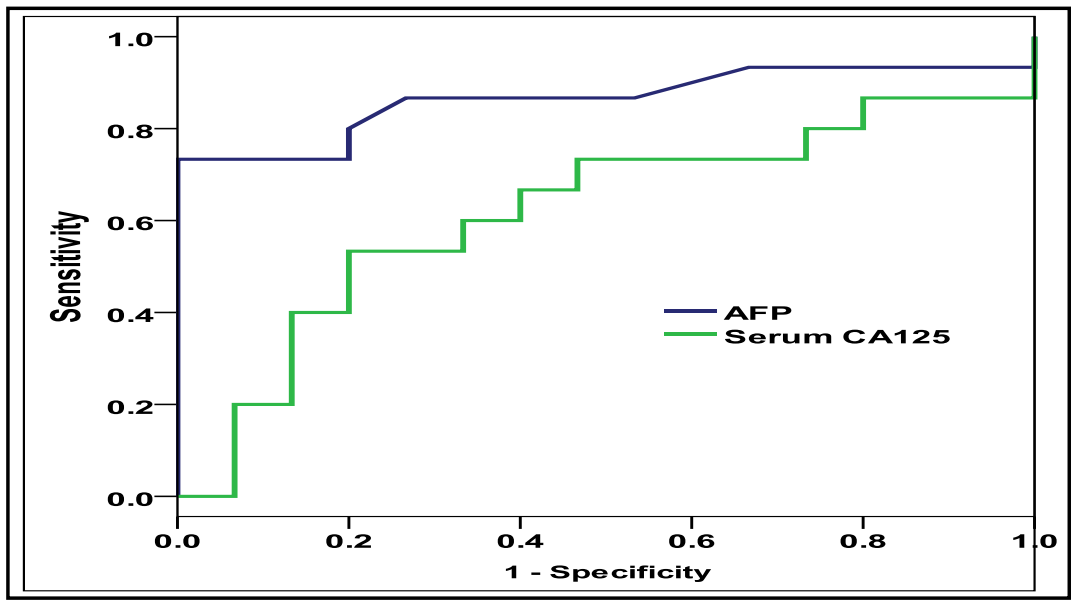

\begin{tabular}{|l|c|c|c|c|c|}
\hline Lab & AUC & SE & P & 95\% CI & Cutoff \\
\hline AFP & $\mathbf{0 . 8 6 4}$ & $\mathbf{0 . 0 7 6}$ & $<\mathbf{0 . 0 0 1} *$ & $\mathbf{0 . 6 9 6 - 1 . 0 0 0}$ & $\geq \mathbf{2 6 . 0}$ \\
\hline Serum CA125 & $\mathbf{0 . 6 1 8}$ & $\mathbf{0 . 1 0 7}$ & $\mathbf{0 . 2 7 2}$ & $\mathbf{0 . 4 0 8 - 0 . 8 2 8}$ & -- \\
\hline
\end{tabular}

AUC: Area under curve, SE: Standard error, CI: Confidence interval, *Significant

Figure (1): ROC curve for AFP and serum CA125 in differentiating compensated HCC group (C) and non-HCC group (A). 


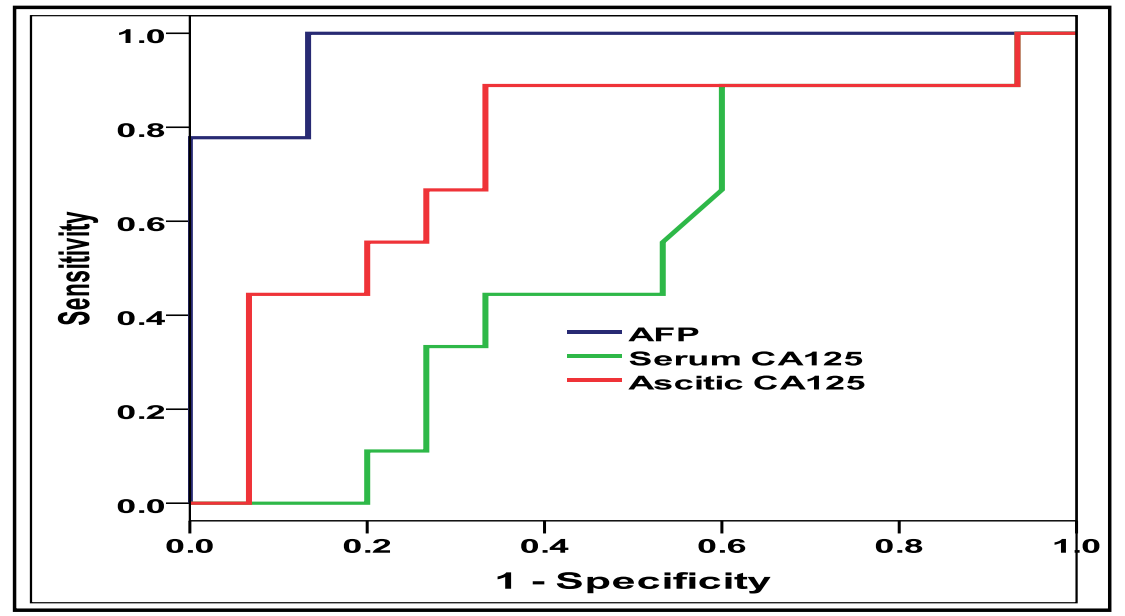

\begin{tabular}{|l|c|c|c|c|c|}
\hline Lab & AUC & SE & P & 95\% CI & Cutoff \\
\hline AFP & $\mathbf{0 . 9 7 0}$ & $\mathbf{0 . 0 2 9}$ & $<\mathbf{0 . 0 0 1} *$ & $\mathbf{0 . 0 0 0 - 1 . 0 0 0}$ & $\geq 11.5$ \\
\hline Serum CA125 & $\mathbf{0 . 5 2 2}$ & $\mathbf{0 . 1 2 1}$ & $\mathbf{0 . 8 5 8}$ & $\mathbf{0 . 2 8 6 - 0 . 7 5 9}$ & -- \\
\hline Ascitic CA125 & $\mathbf{0 . 7 4 1}$ & $\mathbf{0 . 1 1 2}$ & $\mathbf{0 . 0 5 3}$ & $\mathbf{0 . 5 2 1 - 0 . 9 6 1}$ & -- \\
\hline
\end{tabular}

AUC: Area under curve, SE: Standard error, CI: Confidence interval, *Significant

Figure (2): ROC curve for AFP and serum CA125 in differentiating decompensated HCC (D) group from non-HCC (B) group

\section{DISCUSSION}

It may be one of the first Egyptian studies that assessed the correlation between CA-125 and compensated and decompensated CLD with or without HCC.

Regarding the serum level of CA125, there was a significant elevation in both compensated group (A) and decompensated group (B) post $\mathrm{HCV}$ cirrhotic cases but more higher in decompensated group (B), this in agreement with each of; Piekarska et al. [14], who stated that the mean serum levels of CA-125 in patients with cirrhosis (with and without ascites) were elevated above the normal level, Xiao and Liu [15] who found the elevation of CA-125 in sera of cirrhotic patients without ascites and Assmar et al. [16] who reported that CA-125 was not a tissue or tumor specific antigen, elevated level could be detected in patient without malignant transformation and indicate presence of cirrhosis in benign liver disease cases.

There was a significant positive correlation between serum level and ascetic level of CA125 in both non HCC (B) and HCC (D) decompensated groups and this was in a harmony with Hussain and Camilleri [17] who suggested that simultaneous assay of CA-125 in serum and body fluid and/or with a panel of other tumor marker could be accurate in diagnosing malignant and non malignant cases, also significant elevation of CA-125 could occur in HCC cases. Also Tuzun et al. [18] reported a positive correlation between serum and ascitic fluid levels of CA-125, however ascitic fluid levels were higher than serum levels, which explained that the antigen is mesothelial rather than tumoral origin. However our results reported that the ascitic level of $\mathrm{Ca} 125$ was elevated in decompensated HCC group (D) than non HCC group (B), this supported that the antigen origin may be from both mesothelial and tumoral cells.

Regarding the correlation between AFP and CA125 serum and ascitic level; Only AFP had significant diagnostic performance in differentiating compensated and decompensated HCC groups (C) \& (D) from non-HCC groups (A) \&(B). However Lopez et al. [19] who stated that AFPCA-125 combination had the highest sensitivity to diagnose $96 \%$ of the HCC patients, also both could be combined for HCC screening due to their excellent sensitivity and specificity, respectively: a negative result for both, or even CA 125 alone, would discourage $\mathrm{HCC}$ diagnosis, while positive results of both would make HCC presence highly probable. A positive CA 125 and negative AFP would be equivocal for HCC. Also Elias and Kew [20] reported that CA 125 has a highly sensitivity but lacks specificity for HCC diagnosis. 
Funding: None.

\section{Conflicts of interest: None.}

Ethical approval:Approved ; written consents have been taken from all included patients.

\section{REFERENCES}

1. Aref S, Mabed M, Selim T, Goda T, Khafagy N. Thrombobiotin (THO) level in hepatic patients with thrombocytopenia. Hematology, 2004; (5-6): 351-356.

2. Schuppan D, Afdhal, H. Liver Cirrhosis. Lancet 2008; 371(9615): 838-851.

3. Ackermann D. Treatment of ascites, hyponatremia and hepatorenal syndrome in liver cirrhosis. Ther. Umsch 2009; 66(11): 747-51.

4. Sevinc A, Camci C, Turk HM, Buyukberber S. How to interpret serum CA125 levels in patients with serosal involvement? A clinical dilemma. Oncology 2003; 65: 1-6.

5. Duffy MJ, Bonfrer JM, Kulpa J, Rustin GJ, Soletormos G, Torre GC, et.al. CA125 in ovarian cancer: European Group on Tumor Markers guidelines for clinical use. Int J Gynecol Cancer 2005; 15(5):679-91.

6. Singhal A, Lander E, Karachristos A, Daly E, Dowling P, Patel V, et al. Elevation of CA 125 and CA 19-9 in patients with end-stage liver disease. Int J Biol Markers 2012; 27 (2):147-151.

7. Kalantari Y, Naik G, Joshi SP, Jain A, Phatak $\mathrm{S}$, Chavan R, et al. Raised CA-125 in non-malignant pleural and ascetic fluid samples. Indian $\mathrm{J} \mathrm{Med}$ Res 2007; 125: 25-30.

8. Shaker M. Epidemiology of HCC in Egypt. Gastroenterol Hepatol Open Access 2016; 4(3): 00097.

9. Soresi M, Magliarisi C, Campagna P, Leto G, Bonfissuto G, Riili A, et al. Usefulness of alphafetoprotein in the diagnosis of hepatocellular carcinoma. Anticancer Res 2003; 23: 1747-1753.

10. Bae JS, Park SJ, Park KB, Paik SY, Ryu JK, Choi $\mathrm{CK}$, et al. Acute exacerbation of hepatitis in liver cirrhosis with very high levels of alpha- fetoprotein but no occurrence of hepatocellular carcinoma. Korean J Intern Med 2005; 20: 80-85.

11. Lopez JB, Balasegaram, M, Thambyrajah V. Serum CA125 as a marker of hepatocellular carcinoma. Int J BiolMarkers 1996; 11:178-82.

12. Esmat G, Shaker MK, El-folly RF, Omar A, ElMetanawy W, El Dorry A, et al. Towards an Egyptian Guideline from Screening to Treatment of Hepatocellular Carcinoma. The Afro-Arab Liver Journal 2009; 8(3):107-112.

13. Roche.com: Roche diagnostics GmbH Sandhover Strasser 116, D-68305 Mannheim.

14. Piekarska A, Janusz P, Joanna, Z. Elevated levels of cancer antigen CA-125 in patients with chronic liver diseases with and without ascites. $E \& C$ Hepatology 2005; 3(1): 30-33.

15. Xiao WB, Liu, YL. Elevation of serum and ascites cancer antigen 125 levels in patients with liver cirrhosis. J. Gastroenterol Hepatol 2003; 18: $1315-16$.

16. Assmar M, Yeganeh S, Mansourghanaei F, Amir-Mozafari N. Combined Evaluation of AFP, CA15-3, CA125, CA19-9, and CEA Tumor Markers in Patients with Hepatitis B and C. Iran J. Public 2016; 45(12):1645-1651.

17. Hussain SF, Camilleri P. Elevation of tumor marker CA-125 in serum \& body fluids: interpret with caution. Indian J Med Res 2007, 125: 10-12.

18. Tuzun Y, Celik Y, Bayan K, Yilmaz S, Dursun M, Canoruc F. Correlation of tumour markers in ascitic fluid and serum: are measurements of ascitic tumour markers a futile attempt? J Int Med Res 2009; 37:79-86.

19. Lopez JB, Balasegaram M F, Timor J and Thambyrajah V. Comparison of alpha-fetoprotein with some other tumour markers in Malaysians with hepatocellular carcinoma. Malaysian $J$ Pathol 1997; 19(1): 53 - 58.

20. Elias J, Kew MC. Evaluation of CA 125 as a serum marker of hepatocellular carcinoma. Int $J$ Cancer 1990; 46: 805-7. 